\title{
EFICÁCIA DO INSETICIDA PIRIPROXIFEM ISOLADO OU EM ASSOCIAÇÕES NO CONTROLE DE Enneothrips flavens NA CULTURA DO AMENDOIM
}

Carlos César de Oliveira Guarnierii; Tamara Ribeiro Silva²; Luciano Hiroyuki Kajihara ${ }^{3}$; Renato Paes Júnior $^{4}$

${ }^{1}$ Engenheiro Agrônomo, Rotam do Brasil, Artur Nogueira, SP, carlosguarnieri@rotam.com; ${ }^{2}$ Engenheira Agrônoma, Rotam do Brasil, Artur Nogueira, SP; ${ }^{3}$ Doutorando em Fitopatologia, Instituto Biológico, Campinas, SP; ${ }^{4}$ Engenheiro Agrônomo, Rotam do Brasil, Artur Nogueira, SP.

RESUMO: O amendoim é alvo de diversas pragas, dentre elas se destaca o tripes (Enneothrips flavens Moulton 1941), que provoca estrias e deformações nos folíolos, e consequentemente grandes perdas de produtividade. O principal método de controle desse inseto é o químico. Portanto, o estudo teve como objetivo avaliar o efeito da aplicação do inseticida piriproxifem isolado ou em associações sobre adultos de $E$. flavens. Utilizou-se delineamento em blocos casualizados, com 8 tratamentos e 4 repetições. Os tratamentos foram piriproxifem isolado ou em mistura com imidacloprido ou lambda cialotrina, imidacloprido, acefato e tiametoxam + lambda cialotrina. Com base nos resultados todos os tratamentos diferiram estatisticamente da testemunha aos 14 dias após a aplicação, piriproxifem + lambda cialotrina $(25+9)$ foi o tratamento com melhor percentual de controle, apresentando controle próximo a $90 \%$ em todas as avaliações. Piriproxifem isolado possui efeito mais lento no controle da praga.

Palavras-Chave: tripes, controle químico, Arachis hypogaea

\section{INTRODUÇÃO}

A área plantada de amendoim (Arachis hypogaea) no Brasil esta estimada em 138,7 mil hectares, com produção de 478,7 mil toneladas e produtividade média de 3,452 kg/ha (CONAB, 2018). Essa produtividade pode ser afetada por diversos fatores, principalmente por doenças e pragas.

Uma das principais pragas no Brasil é o tripes, E. flavens, que possui ocorrência generalizada, elevados níveis populacionais e causa grandes danos à cultura (GALLO et al., 2002). O tripes extrai o conteúdo celular da planta, formando áreas descoradas e com formação de necrose (LIMA, 1938), provocando assim o crescimento anormal da planta. Em tecidos desenvolvidos, o ataque provoca uma aparência prateada ao tecido atacado (JAGER \& BUTÔT, 1993). A utilização de inseticidas tem sido o método principal e mais eficaz para o controle dessa praga (LASCA et al., 1983). Atualmente os principais grupos de inseticidas usados são os piretróides, carbamatos, alguns reguladores de crescimento e produtos fosforados.

Com isso, o objetivo deste trabalho é avaliar o efeito da aplicação do inseticida piriproxifem isolado ou em associações sobre ninfas e adultos de E. flavens. 


\section{MATERIAL E MÉTODOS}

O experimento foi realizado em campo, na estação experimental da ROTAM em Artur Nogueira, com a cultivar IAC OL3, semeada em janeiro de 2018, em espaçamento 0,5 m. O delineamento utilizado foi de blocos ao acaso com 4 repetições e 8 tratamentos, cada parcela era composta por 3 metros de largura por 6 metros de comprimento. Os tratamentos foram em g.i.a/ha: 1piriproxifem (25); 2- piriproxifem + lambda cialotrina $(25+9)$; 3- piriproxifem + imidacloprido $(25+$ $105)$; 4- piriproxifem + imidacloprido $(25+105)$; 5-lambda cialotrina + tiametoxam $(31,8+35,2)$; 6- imidacloprido (105); 7- acefato $(637,5)$; 8- testemunha. Foi realizada uma pulverização aos 50 DAP, utilizando-se equipamento costal pressurizado a $\mathrm{CO}_{2}$, equipado com uma barra de $3 \mathrm{~m}$, com 6 bicos tipo leque XR110 02 espaçados de 0,5 m entre si, calibrados para aplicar 200L.ha de calda. Avaliou-se o número de adultos e ninfas de tripes em 10 folíolos ao acaso nas linhas centrais da parcela, previamente a aplicação, e aos 5, 11 e 14 dias após a aplicação (DAA). Os dados obtidos foram analisados estatisticamente e as médias comparadas pelo teste de Scott\&Knott a $5 \%$ de probabilidade. A porcentagem de controle foi definida utilizando-se a fórmula de Henderson \& Tilton (1955), que contempla as variações na infestação de insetos na testemunha e nos tratamentos, pré e pós aplicação.

\section{RESULTADOS E DISCUSSÃO}

Em relação ao nível populacional, todos os tratamentos diferiram estatisticamente da testemunha aos 14 dias após a aplicação (DAA), sendo que a presença de1 tripes por 4 folíolos é suficiente para causar o sintoma do prateamento nas plantas de amendoim (SIMITH JUNIOR \& BARFIELD, 1982) (TABELA 1). Na porcentagem de controle aos 5 DAA, o tratamento de menor porcentagem de controle foi o piriproxifem isolado, porém aos 14 DAA, o mesmo se mostrou eficiente com controle superior a 70\% (Tabela 2). Devido ao hábito desses insetos se abrigarem entre os folíolos, o uso de produtos sistêmicos apresenta um bom controle na cultura do amendoim. (GALLI \& ARRUDA, 1989). Nas avaliações realizadas aos 14 DAA os tratamentos com lambda cialotrina + tiametoxam e imidacloprido foram similares em controle, com 59 e 55\%, respectivamente. Nos tratamentos em que foi adicionado o piriproxifem, houve acréscimo de controle, em especial aos tratamentos com piriproxifem + lambda cialotrina $(25+9$ g.i.a/ha) e piriproxifem + imidacloprido $(25$ +105 g.i.a/ha) que obtiveram incrementos de 14 e $22 \%$ em relação ao tratamento com piriproxifem e imidacloprido isolados. 
16 e 17 de agosto de 2018, centro de convenções da FCAV/UNESP - Câmpus de Jaboticabal, SP

Tabela 1. Análise de variância e teste de comparação de médias do número de tripes (adulto e ninfas) em 10 folíolos.

\begin{tabular}{lrrcc}
\hline Tratamentos & Prévia & 5 DAA & 11 DAA & 14 DAA \\
\hline Piriproxifem (25) & $4,5 \mathrm{a}$ & $2,7 \mathrm{a}$ & $3,7 \mathrm{a}$ & $2 \mathrm{~b}$ \\
Piriproxifem + lambda cialotrina $(25+9)$ & $6,2 \mathrm{a}$ & $0,75 \mathrm{a}$ & $2,5 \mathrm{a}$ & $1,2 \mathrm{~b}$ \\
Piriproxifem + imidacloprido $(25+105)$ & $3,7 \mathrm{a}$ & $1,2 \mathrm{a}$ & $3,0 \mathrm{a}$ & $1,5 \mathrm{~b}$ \\
Piriproxifem + imidacloprido $(25+105)$ & $3,7 \mathrm{a}$ & $0,5 \mathrm{a}$ & $2,2 \mathrm{a}$ & $2 \mathrm{~b}$ \\
Lambda cialotrina + tiametoxam $(31,8+35,2)$ & $4,2 \mathrm{a}$ & $1,5 \mathrm{a}$ & $3,2 \mathrm{a}$ & $3 \mathrm{~b}$ \\
Imidacloprido (105) & $5,7 \mathrm{a}$ & $0,75 \mathrm{a}$ & $2,7 \mathrm{a}$ & $2 \mathrm{~b}$ \\
Acefato $(637,5)$ & $5,2 \mathrm{a}$ & $1,0 \mathrm{a}$ & $1,5 \mathrm{a}$ & $2,5 \mathrm{~b}$ \\
Testemunha & $2,7 \mathrm{a}$ & $2,0 \mathrm{a}$ & $4,2 \mathrm{a}$ & $4,7^{\mathrm{a}}$ \\
\hline F & $0,48^{\mathrm{NS}}$ & $0,56^{\mathrm{NS}}$ & $1,15^{\mathrm{NS}}$ & $3,07^{*}$ \\
\hline
\end{tabular}

Médias seguidas de mesma letra na coluna não diferem entre si pelo teste de Scott\&Knott a $5 \%$ de probabilidade; ${ }^{N S}$ : Não significativo a $5 \%$ de probabilidade pelo teste $\mathrm{F} .{ }^{*}$ Diferença significativa a $5 \%$ de probabilidade pelo teste $\mathrm{F}$.

Tabela 2. Porcentagem de controle de acordo com a fórmula de Henderson \& Tilton (1955) em ensaio de eficácia de inseticidas sobre o E. flavens.

\begin{tabular}{lrrc}
\hline Tratamentos & 5 DAA & 11 DAA & 14 DAA \\
\hline Piriproxifem (25) & 16 & 46 & 74 \\
Piriproxifem + lambda cialotrina $(25+9)$ & 84 & 90 & 88 \\
Piriproxifem + imidacloprido $(25+105)$ & 54 & 48 & 77 \\
Piriproxifem + imidacloprido $(25+105)$ & 82 & 61 & 69 \\
Lambda cialotrina + tiametoxam $(31,8+35,2)$ & 51 & 51 & 59 \\
Imidacloprido (105) & 31 & 56 & 55 \\
Acefato (637,5) & 74 & 82 & 72 \\
Testemunha & 0 & 0 & 0 \\
\hline
\end{tabular}

\section{CONCLUSÃO}

Com base nos resultados obtidos, conclui-se que piriproxifem + lambda cialotrina $(25+9$ g.i.a/ha) foi o tratamento com melhor percentual de controle, apresentando controle próximo a $90 \%$ em todas as avaliações, apesar de não diferir estatisticamente dos outros tratamentos químicos quanto a população de insetos nos folíolos. Piriproxifem isolado possui efeito mais lento no controle da praga.

\section{REFERÊNCIAS BIBLIOGRÁFICAS}

CONAB - Companhia Nacional de Abastecimento. Brasil. Acompanhamento de safra Brasileira: grãos.Brasília,2018. $126 \quad$ p. $\quad$ V.5 $\quad$ - $\quad$ SAFRA 17/18. Disponível em: http://www.agricultura.gov.br/noticias/safra-de-graos-podera-atingir-227-9-milhoes-de-toneladas-em2017-2018/AcompanhamentodaSafraBrasileiradeGros4Levantamento20172018.pdf.Acesso em: 22 maio de 2018. 
GALLO, D.; NAKANO, O.; SILVEIRA NETO, S.; CARVALHO, R.P.L.; BATISTA, G.C.; BERTI FILHO, E.; PARRA, J.R.P.; ZUCCHI, R.A.; ALVES, S.B.; VENDRAMIN, J.D.; MARCHINI, L.C.; LOPES, J.R.S. \& OMOTO, C. Entomologia Agrícola. Piracicaba: FEALQ, 920p, 2002.

GALLI, J.C.; ARRUDA, A.C. Aplicação de Cypermetrina 30 ED em controle experimental de Enneothrips flavens Moulton, 1941 (Thysanoptera, Thripidae) em ultra baixo volume em cultivo de amendoim. Ver. Agric., v.64, n.1, p.21-34, 1989.

HENDERSON, C.F.; TILTON, E.W. Tests with acaricides against the brown wheat mite. Journal of Economic Entomology, v.48, p.157-161, 1955.

JAGER, C.M. \& BUTÔT, R.P.Y. Chrysanthemum resistance to two types of thrips (Frankliniella occidentalis Pergande) feeding damage. Proceedings of Experimental and Applied Entomology, Amsterdam, v. 4, n.2, p. 27-31, 1993.

LASCA, D. H. C., GODOY, I. J., MARIOTTO, P. R., MORAES, S. A., JOCYS, T., ROSTON, A. J., PRATES, H. S.; PELEGRINETTI, J. R. Controle de pragas e doenças da cultura do amendoim. Campinas, 1983. p. 10. (Boletim Técnico, 174).

LIMA, A. C. Ordem Thysanoptera. In: Insetos do Brasil. Rio de Janeiro, ENA, 1938, t. 1, p. 405-52.

SMITH Jr., J.W. \& BARFIELD, C.S. Management of preharvest insects. In: PATTEE, H.E. \& YOUNG, C.T. (ed.) Peanut Science and Tecnology. Texas, p. 250-325, 1982. 